\title{
Dynamic amino-acid PET in neuro-oncology: a prognostic tool becomes essential
}

\author{
Antoine Verger ${ }^{1,2,3} \cdot$ Laëtitia Imbert ${ }^{1,2} \cdot$ Timothée Zaragori $^{1,2}$ \\ Published online: 13 September 2021 \\ (c) The Author(s), under exclusive licence to Springer-Verlag GmbH Germany, part of Springer Nature 2021
}

Amino-acid PET imaging is an efficient complementary tool to MRI for the assessment of gliomas, principally for high-grade gliomas [1] and is now recommended by the Response Assessment in Neuro-Oncology Group (RANO) [2]. ${ }^{11} \mathrm{C}$-methyl-L-methionine $\left({ }^{11} \mathrm{C}-\mathrm{MET}\right), \mathrm{O}-2-{ }^{18} \mathrm{~F}$-fluoroethyl-L-tyrosine $\left({ }^{18} \mathrm{~F}\right.$-FET) and 3,4-dihydroxy-6- ${ }^{18} \mathrm{~F}$-fluoro$\mathrm{L}$-phenylalanine $\left({ }^{18} \mathrm{~F}\right.$-FDopa $)$ are the three main aminoacid radiotracers used in neuro-oncology PET imaging, with most published studies based on ${ }^{18}$ F-FET [1-3]. Most nuclear medicine centres only analyse static acquisitions of amino-acid PET imaging. These static acquisitions have proven effective for diagnosing gliomas and for defining the extent of tumour involvement and are particularly useful for treatment planning [4-9]. The European guidelines nevertheless introduced dynamic amino-acid PET utility for the assessment of gliomas [3] and numerous publications on dynamic amino-acid PET imaging also report that this approach yields additional information about tumour biology. Although amino-acid PET imaging primarily detects the expression of L-amino-acid transporters (LAT) in gliomas, additional dynamic parameters may reveal characteristics relating to perfusion and therefore identify features of tumour neovascularization [10].

Several studies initially investigated dynamic analyses in gliomas using ${ }^{18} \mathrm{~F}$-FET [11], then ${ }^{18} \mathrm{~F}$-FDopa [12] and even ${ }^{11} \mathrm{C}$-MET [13], notwithstanding the short radioactive period of the ${ }^{11} \mathrm{C}$ radio-isotope. Dynamic analysis is based

This article is part of the Topical Collection on Oncology-Brain

Antoine Verger

a.verger@chru-nancy.fr

1 Department of Nuclear Medicine \& Nancyclotep Imaging Platform, CHRU-Nancy, Université de Lorraine, F-54000 Nancy, France

2 INSERM, IADI, UMR 1254 Université de Lorraine, F-54000 Nancy, France

3 Médecine Nucléaire, Hôpital de Brabois, CHRU-Nancy, Allée du Morvan, 54500 Vandoeuvre-les-Nancy, France on the assumption that aggressive gliomas (i.e. high-grade gliomas and/or IDH-wildtype gliomas) have high tracer uptake within the first few minutes post-injection (washin), followed by a decrease in the uptake curve (wash-out), while less aggressive gliomas (i.e. low-grade gliomas and/ or IDH-mutant gliomas) typically show a slow increase in amino-acid uptake with the highest values observed during later time frames. As initially suggested by Pöpperl et al. [11], the washout observed in high-grade gliomas might be indicative of micro vessel density and LAT expression but also of disruption of the blood-brain barrier. To date, aminoacid PET dynamic analysis studies have contributed to position dynamic analysis as an essential component of glioma prognostic information and as a useful complementary tool to static images. The prognostic information for glioma kinetic amino PET analysis can be obtained from a scan of only 30-40 $\mathrm{min}$ [14]. This represents a significant reduction in the acquisition time normally required for dynamic PET, which had previously restricted the wider application of the analysis in clinical practice. Dynamic PET studies predominantly focus on two parameters extracted from the tumour volume of interest, namely, the time-to-peak (TTP), which represents the time from the beginning of the injection to the maximum SUV, and the slope, which is typically a linear regression of the late phase of the time-activity curve (TAC).

Most of the prognostic information from molecular parameters, which is included in the WHO 2016 classification of gliomas [15], is derived from dynamic PET parameters. It has become crucial to non-invasively determine glioma molecular parameters, such as IDH mutation status, since they are associated with better patient outcome [15]. Irrespectively of whether dynamic parameters are based on ${ }^{18}$ F-FET $[16,17]$ or ${ }^{18}$ F-FDopa PET imaging [12], they predict the presence of an IDH mutation at the initial diagnosis with accuracies ranging from 72 to $79 \%[12,16,17]$. Static parameters were unable to provide IDH mutation status or provided lower performances. In addition, the prognostic value of dynamic parameters persists even when taking 
into account PET textural features [18, 19], numerous other quantitative features derived from static images. Indeed, the Zaragori et al. radiomics study reports an accuracy of $74 \%$ for predicting IDH mutations, with the TTP dynamic feature accounting for $35.5 \%$ of this predictive value [19]. Dynamic amino-acid PET parameters are even able to identify different patient outcomes within the same histologically defined group [20-22]. For example, although lower tumour-tobackground ratios in static images and longer median TTP in dynamic images were both associated with better glioma outcomes, only TTP was specifically associated with better outcomes in the IDH-mutant astrocytoma group [23]. Longer TTP values also identified increased PFS within the IDH-wildtype glioma group, whereas none of the static parameters considered was associated with PFS [24]. TTP is also an independent predictor of OS in this IDH-wildtype population [24].

The prognostic value of dynamic imaging is also useful for assessing low-grade gliomas, particularly those imaged without any contrast enhancement on MRI. Low-grade gliomas diagnosed in this manner may indeed harbour highgrade entities or exhibit poor prognostic molecular characteristics which may induce rapid progression [25] and must therefore be detected as early as possible. Decreasing timeactivity curves from the kinetic analysis of newly diagnosed low-grade gliomas were highly prognostic for shorter progression-free survival periods and reduced times to malignant transformation [26]. Moreover, among the suspected low-grade gliomas identified by MRI, kinetic analysis of ${ }^{18} \mathrm{~F}$-FET uptake detected the presence of high-grade gliomas with 95\% sensitivity [27]. These high-grade gliomas would have been missed by the conventional static analysis [27]. These results were recently confirmed in a cohort of gliomas initially diagnosed by MRI without any contrast enhancement. A 5-year follow-up in 98 gadolinium-negative gliomas reveals that increasing, mixed and decreasing TACs were associated with a $85 \%, 47 \%$ and $19 \%$ overall survival, respectively [28].

The prognostic information obtained at initial diagnosis is nevertheless more complicated to apply to glioma recurrences. The prognostic value of static parameters for this particular indication appears to be higher than prognostic values exclusively determined from dynamic parameters $[29,30]$.

The Li et al. publication [31], in the current issue of $E J N$ $M M I$, confirms the high prognostic value of dynamic aminoacid PET parameters at the initial diagnosis by focusing on a specific molecular parameter included in the new cIMPACTNOW future central nervous system tumour classification [32], the telomerase reverse transcriptase promoter (TERTp) mutation. TERTp mutations in IDH-wildtype gliomas are reported to be associated with poor overall survival [33]. In addition to confirming the prognostic value of dynamic
PET acquisitions, Li et al. also provide a novel approach for studying dynamic parameters [31]. Instead of using volumes of interest to extract dynamic parameters of the tumour area, these authors use a voxel-wise analysis. They report that TTP dynamic parametric images non-invasively predict TERTp mutations with an accuracy of $85 \%$ [31]. This foreshadows the novel insights that could be applied to further develop the promise of dynamic acquisitions.

There have been previous reports of voxel-wise analysis in dynamic acquisitions of amino-acid PET imaging in gliomas [34-36]. But the Li et al. study differs from these previous investigations because it evaluates the textural features of TTP parametric images, i.e. by attributing one value of TTP per voxel in the tumour area [31]. This allows to evaluate the heterogeneity of dynamic images and is a similar approach to that used to investigate textural features in static images $[18,19]$, i.e. SUV parametric images. The same authors previously reported no significant predictive value of dynamic parameters for identifying TERTp mutations in newly diagnosed gliomas by using an approach based on volume of interest [37]. Since almost all dynamic PET studies are based on a volume of interest approach, the latest $\mathrm{Li}$ et al. study therefore paves the way to improve predictive performances more generally [31]. The voxel-wise analysis, however, requires kinetic parameters to be fitted, which necessitates long computation times and increases the impact of data noise. In addition, patients' movements must be corrected with great precision to ensure that each voxel is aligned during the whole acquisition. These potential limitations need to be resolved before this type of analysis can be implemented more widely. Another issue to overcome in PET dynamic analysis is to ensure that simplified dynamic models based on time-activity curves of SUV parametric images are representative of tumour metabolism of the amino-acid PET radiotracer. This is the case for the non-metabolized ${ }^{18} \mathrm{~F}$-FET radiotracer [38], but is yet to be investigated for the intracellular metabolized radiotracers ${ }^{18} \mathrm{~F}$-FDopa [39, 40] and ${ }^{11} \mathrm{C}$-MET [36]. Indeed, the fitting of direct kinetic parameters using compartmental models requires the user to provide an input function, which can either be measured invasively from arterial blood samples or extracted from large vessels appearing in the image [36, 41]. These two requirements are very onerous processes in clinical routine practice. Validated and easy-clinically transposable kinetic models will therefore need to be developed for each radiotracer to accurately define brain tumour aminoacid metabolism to allow this approach to be adapted to the clinic.

The latest Li et al. paper [31] and an appraisal of the current literature make a strong case for the widespread use of amino-acid dynamic PET, in all nuclear medicine centres for neuro-oncology imaging, given its high prognostic value. Novel insights in dynamic analyses should help to further 
enhance amino-acid dynamic PET diagnostic performances to better reflect the heterogeneity of gliomas.

\section{Declarations}

Ethics approval Institutional Review Board approval was not required because the paper is an editorial.

Consent to participate Not applicable.

Conflict of interest The authors declare no competing interests.

\section{References}

1. Verger A, Arbizu J, Law I. Role of amino-acid PET in high-grade gliomas: limitations and perspectives. Q J Nucl Med Mol Imaging Off Publ Ital Assoc Nucl Med AIMN Int Assoc Radiopharmacol IAR Sect Soc Of. 2018;62:254-66.

2. Albert NL, Weller M, Suchorska B, Galldiks N, Soffietti R, Kim $\mathrm{MM}$, et al. Response assessment in neuro-oncology working group and European Association for Neuro-Oncology recommendations for the clinical use of PET imaging in gliomas. Neuro-Oncol. 2016;18:1199-208.

3. Law I, Albert NL, Arbizu J, Boellaard R, Drzezga A, Galldiks $\mathrm{N}$, et al. Joint EANM/EANO/RANO practice guidelines/SNMMI procedure standards for imaging of gliomas using PET with radiolabelled amino acids and [18F]FDG: version 1.0. Eur J Nucl Med Mol Imaging. 2019;46:540-57.

4. Sadeghi N, Salmon I, Tang BNT, Denolin V, Levivier M, Wikler $\mathrm{D}$, et al. Correlation between dynamic susceptibility contrast perfusion MRI and methionine metabolism in brain gliomas: preliminary results. J Magn Reson Imaging JMRI. 2006;24:989-94.

5. Fueger BJ, Czernin J, Cloughesy T, Silverman DH, Geist CL, Walter MA, et al. Correlation of 6-18F-fluoro-L-dopa PET uptake with proliferation and tumor grade in newly diagnosed and recurrent gliomas. J Nucl Med Off Publ Soc Nucl Med. 2010;51:1532-8.

6. Rapp M, Heinzel A, Galldiks N, Stoffels G, Felsberg J, Ewelt C, et al. Diagnostic performance of 18F-FET PET in newly diagnosed cerebral lesions suggestive of glioma. J Nucl Med Off Publ Soc Nucl Med. 2013;54:229-35.

7. Goldman S, Levivier M, Pirotte B, Brucher JM, Wikler D, Damhaut $\mathrm{P}$, et al. Regional methionine and glucose uptake in highgrade gliomas: a comparative study on PET-guided stereotactic biopsy. J Nucl Med Off Publ Soc Nucl Med. 1997;38:1459-62.

8. Pafundi DH, Laack NN, Youland RS, Parney IF, Lowe VJ, Giannini C, et al. Biopsy validation of 18F-DOPA PET and biodistribution in gliomas for neurosurgical planning and radiotherapy target delineation: results of a prospective pilot study. Neuro-Oncol. 2013;15:1058-67.

9. Munck Af Rosenschold P, Costa J, Engelholm SA, Lundemann MJ, Law I, Ohlhues L, et al. Impact of [18F]-fluoro-ethyl-tyrosine PET imaging on target definition for radiation therapy of highgrade glioma. Neuro-Oncol. 2015;17:757-63.

10. Liesche F, Lukas M, Preibisch C, Shi K, Schlegel J, Meyer B, et al. 18F-Fluoroethyl-tyrosine uptake is correlated with amino acid transport and neovascularization in treatment-naive glioblastomas. Eur J Nucl Med Mol Imaging. 2019;46:2163-8.

11. Pöpperl G, Kreth FW, Mehrkens JH, Herms J, Seelos K, Koch $\mathrm{W}$, et al. FET PET for the evaluation of untreated gliomas: correlation of FET uptake and uptake kinetics with tumour grading. Eur J Nucl Med Mol Imaging. 2007;34:1933-42.

12. Ginet M, Zaragori T, Marie P-Y, Roch V, Gauchotte G, Rech $\mathrm{F}$, et al. Integration of dynamic parameters in the analysis of 18F-FDopa PET imaging improves the prediction of molecular features of gliomas. Eur J Nucl Med Mol Imaging. 2020 Jun;47(6):1381-90.

13. Nomura Y, Asano Y, Shinoda J, Yano H, Ikegame Y, Kawasaki $\mathrm{T}$, et al. Characteristics of time-activity curves obtained from dynamic 11C-methionine PET in common primary brain tumors. J Neurooncol. 2018;138:649-58.

14. Kratochwil C, Combs SE, Leotta K, Afshar-Oromieh A, Rieken $\mathrm{S}$, Debus J, et al. Intra-individual comparison of $18 \mathrm{~F}-\mathrm{FET}$ and 18F-DOPA in PET imaging of recurrent brain tumors. NeuroOncol. 2014;16:434-40.

15. Louis DN, Perry A, Reifenberger G, von Deimling A, FigarellaBranger D, Cavenee WK, et al. The 2016 World Health Organization classification of tumors of the central nervous system: a summary. Acta Neuropathol (Berl). 2016;131:803-20.

16. Verger A, Stoffels G, Bauer EK, Lohmann P, Blau T, Fink GR, et al. Static and dynamic (18)F-FET PET for the characterization of gliomas defined by IDH and 1p/19q status. Eur J Nucl Med Mol Imaging. 2018 Mar;45(3):443-51.

17. Vettermann F, Suchorska B, Unterrainer M, Nelwan D, Forbrig R, Ruf V, et al. Non-invasive prediction of IDH-wildtype genotype in gliomas using dynamic 18F-FET PET. Eur J Nucl Med Mol Imaging. 2019 Nov;46(12):2581-9.

18. Lohmann P, Kocher M, Steger J, Galldiks N. Radiomics derived from amino-acid PET and conventional MRI in patients with high-grade gliomas. Q J Nucl Med Mol Imaging Off Publ Ital Assoc Nucl Med AIMN Int Assoc Radiopharmacol IAR Sect Soc Of. 2018;62:272-80.

19. Zaragori T, Oster J, Roch V, Hossu G, Chawki MB, Grignon $\mathrm{R}$, et al. 18F-FDOPA PET for the non-invasive prediction of glioma molecular parameters: a radiomics study. J Nucl Med Off Publ Soc Nucl Med. 2021; Ahead of print

20. Jansen NL, Suchorska B, Wenter V, Schmid-Tannwald C, Todica A, Eigenbrod S, et al. Prognostic significance of dynamic 18FFET PET in newly diagnosed astrocytic high-grade glioma. J Nucl Med Off Publ Soc Nucl Med. 2015;56:9-15.

21. Thon N, Kunz M, Lemke L, Jansen NL, Eigenbrod S, Kreth S, et al. Dynamic 18 F-FET PET in suspected WHO grade II gliomas defines distinct biological subgroups with different clinical courses: dynamic PET in Suspected Low-Grade Gliomas. Int J Cancer. 2015;136:2132-45.

22. Mittlmeier LM, Suchorska B, Ruf V, Holzgreve A, Brendel M, Herms J, et al. 18F-FET PET uptake characteristics of long-term IDH-wildtype diffuse glioma survivors. Cancers. 2021;13:3163.

23. Suchorska B, Giese A, Biczok A, Unterrainer M, Weller M, Drexler $\mathrm{M}$, et al. Identification of time-to-peak on dynamic 18F-FET-PET as a prognostic marker specifically in IDH1/2 mutant diffuse astrocytoma. Neuro-Oncol. 2018;20:279-88.

24. Bauer EK, Stoffels G, Blau T, Reifenberger G, Felsberg J, Werner JM, et al. Prediction of survival in patients with IDH-wildtype astrocytic gliomas using dynamic O-(2-[18F]fluoroethyl)-1-tyrosine PET. Eur J Nucl Med Mol Imaging. 2020;47:1486-95.

25. Mandonnet E, Delattre J-Y, Tanguy M-L, Swanson KR, Carpentier $\mathrm{AF}$, Duffau H, et al. Continuous growth of mean tumor diameter in a subset of grade II gliomas. Ann Neurol. 2003;53:524-8.

26. Jansen NL, Suchorska B, Wenter V, Eigenbrod S, Schmid-Tannwald C, Zwergal A, et al. Dynamic 18F-FET PET in newly diagnosed astrocytic low-grade glioma identifies high-risk patients. J Nucl Med Off Publ Soc Nucl Med. 2014;55:198-203.

27. Jansen NL, Graute V, Armbruster L, Suchorska B, Lutz J, Eigenbrod S, et al. MRI-suspected low-grade glioma: is there a need 
to perform dynamic FET PET? Eur J Nucl Med Mol Imaging. 2012;39:1021-9.

28. Kunz M, Albert NL, Unterrainer M, la Fougere C, Egensperger $\mathrm{R}$, Schüller U, et al. Dynamic 18F-FET PET is a powerful imaging biomarker in gadolinium-negative gliomas. Neuro-Oncol. 2019;21:274-84.

29. Pyka T, Hiob D, Preibisch C, Gempt J, Wiestler B, Schlegel $\mathrm{J}$, et al. Diagnosis of glioma recurrence using multiparametric dynamic 18F-fluoroethyl-tyrosine PET-MRI. Eur J Radiol. 2018;103:32-7.

30. Zaragori T, Ginet M, Marie P-Y, Roch V, Grignon R, Gauchotte $\mathrm{G}$, et al. Use of static and dynamic 18F-FDopa PET parameters for detecting patients with glioma recurrence or progression. EJNMMI Res. 2020 May 29;10(1):56.

31. Li Z, Kaiser L, Holzgreve A, Ruf VC, Suchorska B, Wenter V, Lietke S, Herms J, Bartenstein P, Tonn J-C, Unterrainer M, Albert NL. Prediction of TERTp-mutation status in IDH-wildtype high-grade gliomas using pre-treatment dynamic 18F-FET PET radiomics. Eur J Nucl Med. 2021. https://doi.org/10.1007/ s00259-021-05526-6.

32. Louis DN, Wesseling P, Aldape K, Brat DJ, Capper D, Cree IA, et al. cIMPACT-NOW update 6: new entity and diagnostic principle recommendations of the cIMPACT-Utrecht meeting on future CNS tumor classification and grading. Brain Pathol. 2020;30:844-56.

33. Eckel-Passow JE, Lachance DH, Molinaro AM, Walsh KM, Decker PA, Sicotte H, et al. Glioma groups based on 1p/19q, IDH, and TERT promoter mutations in tumors. N Engl J Med. 2015;372:2499-508.

34. Blanc-Durand P, Van Der Gucht A, Verger A, Langen K-J, Dunet $\mathrm{V}$, Bloch J, et al. Voxel-based 18F-FET PET segmentation and automatic clustering of tumor voxels: a significant association with IDH1 mutation status and survival in patients with gliomas. PLoS One. 2018 Jun 28;13(6):e0199379.
35. Vomacka L, Unterrainer M, Holzgreve A, Mille E, Gosewisch A, Brosch J, et al. Voxel-wise analysis of dynamic 18F-FET PET: a novel approach for non-invasive glioma characterisation. EJNMMI Res. 2018;8:91.

36. Martens C, Debeir O, Decaestecker C, Metens T, Lebrun L, Leurquin-Sterk G, et al. Voxelwise principal component analysis of dynamic [S-methyl-11C]methionine PET data in glioma patients. Cancers. 2021;13:2342.

37. Unterrainer M, Ruf V, von Rohr K, Suchorska B, Mittlmeier LM, Beyer L, et al. TERT-promoter mutational status in glioblastoma - is there an association with amino acid uptake on dynamic $18 \mathrm{~F}$ FET PET? Front Oncol. 2021;11:645316.

38. Koopman T, Verburg N, Pouwels PJ, Wesseling P, Hoekstra OS, De Witt Hamer PC, et al. Quantitative parametric maps of O-(2[18F]fluoroethyl)-L-tyrosine kinetics in diffuse glioma. J Cereb Blood Flow Metab. 2020;40:895-903.

39. Schiepers C, Chen W, Cloughesy T, Dahlbom M, Huang S-C. 18F-FDOPA kinetics in brain tumors. J Nucl Med Off Publ Soc Nucl Med. 2007;48:1651-61.

40. Wardak M, Schiepers C, Cloughesy TF, Dahlbom M, Phelps ME, Huang S-C. 18F-FLT and 18F-FDOPA PET kinetics in recurrent brain tumors. Eur J Nucl Med Mol Imaging. 2014;41:1199-209.

41. Röhrich M, Huang K, Schrimpf D, Albert NL, Hielscher T, von Deimling A, et al. Integrated analysis of dynamic FET PET/CT parameters, histology, and methylation profiling of 44 gliomas. Eur J Nucl Med Mol Imaging. 2018;45:1573-84.

Publisher's note Springer Nature remains neutral with regard to jurisdictional claims in published maps and institutional affiliations. 